Article

\title{
Synthesis, Crystal Structure, and Properties of a Zn(II) Coordination Polymer Based on a Difunctional Ligand Containing Triazolyl and Carboxyl Groups
}

\author{
Jia-Le Li, Wei-Dong Li, Zi-Wei He, Shuai-Shuai Han and Shui-Sheng Chen *D \\ College of Chemistry \& Chemical Engineering, Fuyang Normal University, Fuyang 236041, China; \\ lijiale_lj1@163.com (J.-L.L); weidongli2018@163.com (W.-D.L.); \\ heziwei_hzw@yeah.net (Z.-W.H.); shuisheng20011@tom.com (S.-S.H.) \\ * Correspondence: fyuniv@163.com
}

Received: 8 October 2018; Accepted: 7 November 2018; Published: 9 November 2018

check for updates

\begin{abstract}
A new compound, namely, $\left[\mathrm{Zn}(\mathrm{L})_{2}\right]_{\mathrm{n}}(\mathbf{1})$ was obtained by the reaction of 2-methyl-4-(4H-1,2, 4-triazol-4-yl) benzoic acid (HL) with $\mathrm{ZnSO}_{4} \cdot 7 \mathrm{H}_{2} \mathrm{O}$, and the compound was characterized by single-crystal X-ray diffraction, infrared spectroscopy, elemental analysis, powder X-ray diffraction (PXRD), and thermogravimetric analysis. The linear HL ligands were deprotonated to be $\mathrm{L}^{-}$anions and act as two-connectors to link $\mathrm{Zn}^{2+}$ to form a two-dimensional (2D) lay structure with $(4,4)$ topology. The large vacancy of $2 \mathrm{D}$ framework allows another layer structure to interpenetrate, resulting in the formation of $2 \mathrm{D}+2 \mathrm{D} \rightarrow 2 \mathrm{D}$ parallel interpenetration in 1 . The weak interactions, such as hydrogen bonding and $\pi-\pi$ stacking interactions, connect the adjacent $2 \mathrm{D}$ layers into a three-dimensional (3D) coordination polymer. The solid-state UV-visible spectroscopy and luminescent property have also been studied.
\end{abstract}

Keywords: supramolecular polymer; crystal structure; spectral property

\section{Introduction}

In recent years, coordination polymers ( $\mathrm{CPs}$ ) built from metal ions and organic ligands have become a hot research topic because of their fascinating architectures and potent applications in the fields of luminescence [1-5], chemical sensors [6], gas adsorption or selective gas adsorption, gas separation [7,8], and heterogeneous catalysis [9]. Generally speaking, the nature of metal ions and organic ligands can greatly affect the properties of CPs [10-15]. Therefore, the elaborate design for organic ligands and the selection of metal ions are the most important factors to obtain desired architectures with favorable properties. Commonly, the N- or O-donor ligands with favorable coordination abilities are extensively employed to build diverse CPs. Among the N-heterocyclic ligands, triazole, imidazole, tetrazole, and pyrazole moieties can not only act as electrically neutral, but also negatively charged muti-dentate bridging ligands to construct CPs [16-20]. For example, we have designed a series of polyazaheteroaromatic ligands including the derivatives of 1, 2, 4-triazole, for example, and 4-imidazoly-containing ligands, such as 1,3,5-tri(1H-imidazol-4-yl) benzene and 1,4-di(1H-imidazol-4-yl) benzene [21,22]. Due to their favorable coordination abilities, they are used to build various porous metal $\mathrm{Cu}$ (II) or $\mathrm{Co}(\mathrm{II})$ imidzolate complexes, which have shown favorable gas adsorption properties in our previous work. Besides the polyazaheteroaromatic ligands, the carboxylic acids show diverse coordination modes and are extensively employed to assemble porous CPs via reticular synthesis by Yaghi's group [23,24]. Significantly, the porous CPs possess a large surface area, as much as $10,000 \mathrm{~m}^{2} / \mathrm{g}$, and greatly exceed those of traditional porous materials, such as zeolites and carbons [23]. Moreover, the different electron configurations of $\mathrm{N}$ and $\mathrm{O}$ atoms cause 
polycarboxylates and N-donors ligands to exhibit different coordination preferences, which produces favorable compatibility for mixed polycarboxylates and N-donors ligands for building CPs $[25,26]$. In this context, we have designed the difunctional organic molecule 4-(1H-imidazol-4-yl) benzoic acid including carboxyl and 4-imidazolyl groups, assembled into two series of $\mathrm{Cu}(\mathrm{II}) / \mathrm{Cu}$ (I) and $\mathrm{Cd}(\mathrm{II})$ complexes due to its diverse coordination modes [27]. Due to their good adjustability for N/O donor ligands, we have designed the new ligand 2-methyl-4-(4H-1,2,4-triazol-4-yl) benzoic acid (HL) including the difunctional 1,2,4-triazol-4-yl and carboxyl groups (Scheme 1) to react with $\mathrm{ZnSO}_{4} \cdot 7 \mathrm{H}_{2} \mathrm{O}$, and synthesized a new $\mathrm{Zn}(\mathrm{II})$ complex $\left[\mathrm{Zn}(\mathrm{L})_{2}\right]_{\mathrm{n}}(\mathbf{1})$ as our extensional study. The UV-vis absorption spectra and luminescent properties of 1 have been studied.

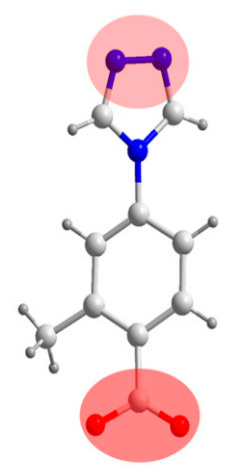

Scheme 1. The structure of 2-methyl-4-(4H-1,2,4-triazol-4-yl) benzoic acid (HL) ligand with difunction groups highlighted in pink circles.

\section{Experimental Section}

\subsection{Materials and Instrumentation}

All the reagents were purchased from Jinan Henhua reagent company (Jinan, China). IR spectra (Nicolet Instrument Inc., Madison, WI, USA) was measured on a Bruker Vector 22 FT-IR spectrophotometer using KBr pellets. Perkin-Elmer 240C Elemental Analyzer (Perkin-Elmer, Inc., Billerica, MA, USA) was used to carry out elemental analyses. Thermogravimetric analyses (TGA) (Perkin-Elmer, Inc., Billerica, MA, USA) was carried out on a simultaneous SDT 2960 thermal analyzer. Power X-ray diffraction pattern was recorded on a Shimadzu XRD-6000 X-ray diffractometer with $\mathrm{CuK} \alpha(\lambda=1.5418 \AA$ A $)$ radiation. A HORIBA FluoroMax-4 fluorescence spectrophotometer (Edinburgh Instruments, Edinburgh, UK) was used to measure photoluminescence spectra and the decay lifetimes.

\subsection{Synthesis of $\left[\mathrm{Zn}(L)_{2}\right]_{n}(\mathbf{1})$}

A mixture of $\mathrm{HL}(0.020 \mathrm{~g}, 0.1 \mathrm{mmol}), \mathrm{ZnSO}_{4} \cdot 7 \mathrm{H}_{2} \mathrm{O}(0.0287 \mathrm{~g}, 0.1 \mathrm{mmol})$, and $\mathrm{NaOH}(0.008 \mathrm{~g}$, $0.1 \mathrm{mmol}$ ) in $12 \mathrm{~mL} \mathrm{H}_{2} \mathrm{O}$ was sealed into a $15 \mathrm{~mL}$ Parr Teflon-lined stainless steel vessel and heated at $140{ }^{\circ} \mathrm{C}$ for $72 \mathrm{~h}$. Colorless block crystals of 1 were obtained (yield, 72\%). Anal. Calcd. (\%) for $\mathrm{C}_{20} \mathrm{H}_{16} \mathrm{~N}_{6} \mathrm{O}_{4} \mathrm{Zn}$ : C, 51.13; H, 3.43; N, 17.89. Found (\%): C, 49.96; H, 3.52; N, 17.78. IR( $\left.\mathrm{KBr}\right)$ : 3620-3245(m), 1598(vs), 1566(s), 1528(m), 1361(vs), 1303(w), 1235(m), 1088(s), 1046(s), 1017(m), 875(m), 789(s), 709(m), 693(w), 655(m), 574(w), 507(w) $\mathrm{cm}^{-1}$.

\subsection{Crystal Structure Determination}

The single-crystal structure for $\left[\mathrm{Zn}(\mathrm{L})_{2}\right]_{\mathrm{n}}(\mathbf{1})$ was collected on a Bruker Smart APEX II charge couple device diffractometer using MoK $\alpha$ radiation $(\lambda=0.71073 \AA)$ at 296(2) K. The structure was solved by the direct method and refined anisotropically on $F^{2}$ refined by the full-matrix least-squares procedure technique using the SHELX-97 program [28]. The crystallographic data and structural refinement are shown in Table 1. 
Table 1. Crystallographic data and structure refinement for $\mathbf{1}$.

\begin{tabular}{|c|c|}
\hline Empirical Formula & $\mathrm{C}_{20} \mathrm{H}_{16} \mathrm{~N}_{6} \mathrm{O}_{4} \mathrm{Zn}$ \\
\hline Formula weight & 469.76 \\
\hline Temperature/K & 296(2) \\
\hline Crystal system & Monoclinic \\
\hline Space group & $P 2_{1} / \mathrm{n}$ \\
\hline$a / \AA$ & $7.6127(6)$ \\
\hline$b / \AA$ & $17.5092(14)$ \\
\hline$c / \AA$ & $14.2027(11)$ \\
\hline$\alpha /^{\circ}$ & 90 \\
\hline$\beta /{ }^{\circ}$ & $97.2370(10)$ \\
\hline$\gamma /{ }^{\circ}$ & 90 \\
\hline Volume $/ \AA^{3}$ & $1878.0(3)$ \\
\hline Z & 4 \\
\hline$\rho_{\text {calc }} \mathrm{mg} / \mathrm{mm}^{3}$ & 1.661 \\
\hline$\mu / \mathrm{mm}^{-1}$ & 1.352 \\
\hline S & 1.042 \\
\hline$F(000)$ & 960 \\
\hline Index ranges & $\begin{aligned}-8 & \leq h \leq 9 \\
-18 & \leq k \leq 21 \\
-17 & \leq l \leq 17\end{aligned}$ \\
\hline Reflections collected & $1 \overline{0} 24 \overline{5}$ \\
\hline Independent reflections & 3694 \\
\hline Data/restraints/parameters & $3694 / 0 / 282$ \\
\hline Goodness-of-fit on $F^{2}$ & 1.042 \\
\hline Final $R$ indexes $[I \geq 2 \sigma(I)]$ & $R_{1}=0.0360, w R_{2}=0.0911$ \\
\hline Final $R$ indexes [all data] & $R_{1}=0.0502, w R_{2}=0.0986$ \\
\hline Largest diff. peak/hole/e $\AA^{-3}$ & $0.866 /-0.323$ \\
\hline
\end{tabular}

Crystallographic data CCDC 1,871,965 for 1 . Copy of the data can be obtained free of charge upon application to CCDC, 12 Union Road, Cambridge CB2 1EZ, UK (Fax: +44-1223-336-033; E-Mail: deposit@ccdc.cam.ac.uk).

\section{Results and Discussion}

\subsection{Preparation}

In this study, we adopted the hydro/solvothermal reaction, because it is an effective method in construction of CPs, especially for the carboxylic acid ligands. Generally, the reaction of metal atoms with carboxylate ligands easily leads to the formation of precipitate, making it difficult to grow suitable single crystals for X-ray diffraction studies. However, a hydro/solvothermal reaction can facilitate crystal growth under the spontaneous reaction system. Coordination polymer 1 was readily prepared with $72 \%$ yield by hydrothermal reaction. The IR spectra exhibit the $\mathrm{O}-\mathrm{H} / \mathrm{C}-\mathrm{H}$ stretching vibration absorption of ligand at the center of $3620-3245 \mathrm{~cm}^{-1}$ for 1 (Figure S1). Strong characteristic bands of carboxyl group are observed in the range of $1598-1528 \mathrm{~cm}^{-1}$ for asymmetric vibrations and $1361 \mathrm{~cm}^{-1}$ for symmetric vibrations, respectively. The typical vibrational band at $1701 \mathrm{~cm}^{-1}$ observed in the IR spectra of HL belongs to the characteristic peak of the carboxyl group, which disappeared in coordination with polymer $\mathbf{1}$, showing the carboxyl group was deprotonated and participated in coordination with $\mathrm{Zn}$ (II) metal atom.

\subsection{Crystal Structure of $\left[\mathrm{Zn}(L)_{2}\right]_{n}(\mathbf{1})$}

X-ray diffraction analysis showed that $\left[\mathrm{Zn}(\mathrm{L})_{2}\right]_{\mathrm{n}}(\mathbf{1})$ crystallizes in the monoclinic $P 2_{1} / \mathrm{c}$ space group. One crystallographically independent $\mathrm{Zn}(\mathrm{II})$ atom and two $\mathrm{L}^{-}$ligands are included in the asymmetric unit. As shown in Figure 1, each $\mathrm{Zn}$ (II) atom possesses a distorted tetrahedral geometry and is coordinated by two oxygen atoms $(\mathrm{O} 1, \mathrm{O} 3)$ from two different $\mathrm{L}^{-}$ligands and 
two nitrogen atoms (N1) from another two distinct $\mathrm{L}^{-}$ligands. The $\mathrm{Zn}-\mathrm{O}$ bond lengths are 1.931(2) and 1.938(2) $\AA$, and the Zn-N bond lengths are 2.024(2) and 2.042(2) $\AA$ (Table S1). The bond angles around the center $\mathrm{Zn}(\mathrm{II})$ atom are in the range of $99.64(10)-124.08(10)^{\circ}$ (Table S1). Both of the $\mathrm{L}^{-}$ ligands in $\mathbf{1}$ have the same coordination mode and act as two-connectors to link two metal $\mathrm{Zn}$ (II) atoms. In 1, the $\mathrm{L}^{-}$ligands links $\mathrm{Zn}$ (II) ions to form a two-dimensional $(2 \mathrm{D})(4,4)$ layer structure (Figure 2), where the lateral $\mathrm{Zn} \cdots \mathrm{Zn}$ distances are 11.54 and $11.66 \AA$, and the diagonal $\mathrm{Zn} \cdots \mathrm{Zn}$ distances are 15.22 and $17.51 \AA$. The large vacancy of the 2D framework allows another same layer structure to interpenetrate, resulting in the formation of $2 \mathrm{D}+2 \mathrm{D} \rightarrow 2 \mathrm{D}$ parallel interpenetration in 1 (Figure 3) [29]. Compared with the reported 4-(4H-1,2,4-triazol-4-yl) benzoic acid ligand (CPT), the HL ligand employed in this study has a methyl group at 2-position that can build a different framework from the ones originated from CPT ligand. For example, the Liu group employed the CPT ligand to build two isomeric $\mathrm{Zn}(\mathrm{II})$-based metal-organic frameworks $\left\{\left[\mathrm{Zn}(\mathrm{CPT})_{2}\right](\mathrm{NMF})_{3}\right\}_{\mathrm{n}}$ and $\left\{\left[\mathrm{Zn}(\mathrm{CPT})_{2}\right](\mathrm{DMF})_{0.75}\right\}_{\mathrm{n}}(\mathrm{NMF}=\mathrm{N}$-methylformamide, $\mathrm{DMF}=\mathrm{N}, \mathrm{N}$-dimethylformamide) with the same 4 -fold interpenetrated dia topological network [30]. The study further demonstrates that the ligand has great effect on the resulting coordination framework. Moreover, the $\mathrm{O}$ and $\mathrm{N}$ atoms from imidazolyl or carboxyl groups can act as the acceptor for hydrogen bonding, thus easily benefiting the formation of supramolecular polymers [31]. As a result, there exists rich hydrogen bonding interaction in 1, and the $\mathrm{C}-\mathrm{H} \cdots \mathrm{O}\left(\mathrm{C}(1) \cdots \mathrm{O}(2) 3.424(4) \AA, \mathrm{C}(1)-\mathrm{H}(1) \cdots \mathrm{O}(2) 152^{\circ} ; \mathrm{C}(4) \cdots \mathrm{O}(2) 2.794(4) \AA, \mathrm{C}(4)-\mathrm{H}(4) \cdots \mathrm{O}(2)\right.$ $100^{\circ} ; \mathrm{C}(7) \cdots \mathrm{O}(4) 3.123(4) \AA, \mathrm{C}(7)-\mathrm{H}(7) \cdots \mathrm{O}(4) 138^{\circ} ; \mathrm{C}(11) \cdots \mathrm{O}(4) 2.809(4) \AA, \mathrm{C}(11)-\mathrm{H}(11) \cdots \mathrm{O}(4) 100^{\circ}$;

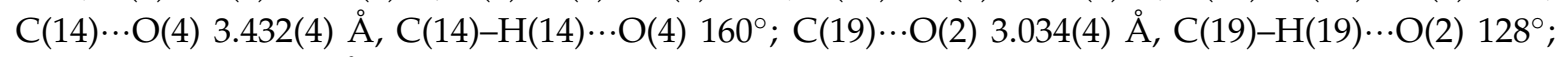
$\mathrm{C}(20) \cdots \mathrm{O}(4) 3.125(4) \AA, \mathrm{C}(20)-\mathrm{H}(20) \cdots \mathrm{O}(4) 152^{\circ}$ hydrogen bonds are extensively distributed among the $2 \mathrm{D}$ layers (Table S2). Moreover, the two benzene rings of $\mathrm{L}^{-}$ligands from the neighboring $2 \mathrm{D}$ layers are parallel and separated by a centroid-centroid distance of $3.48 \AA$, exhibiting classic weak $\pi-\pi$ stacking interactions [32]. In this context, a three-dimensional (3D) coordination polymer is built through the connections originating from the weak interactions, including hydrogen bonding and $\pi-\pi$ stacking interactions between the adjacent 2D layers (Figure 4).

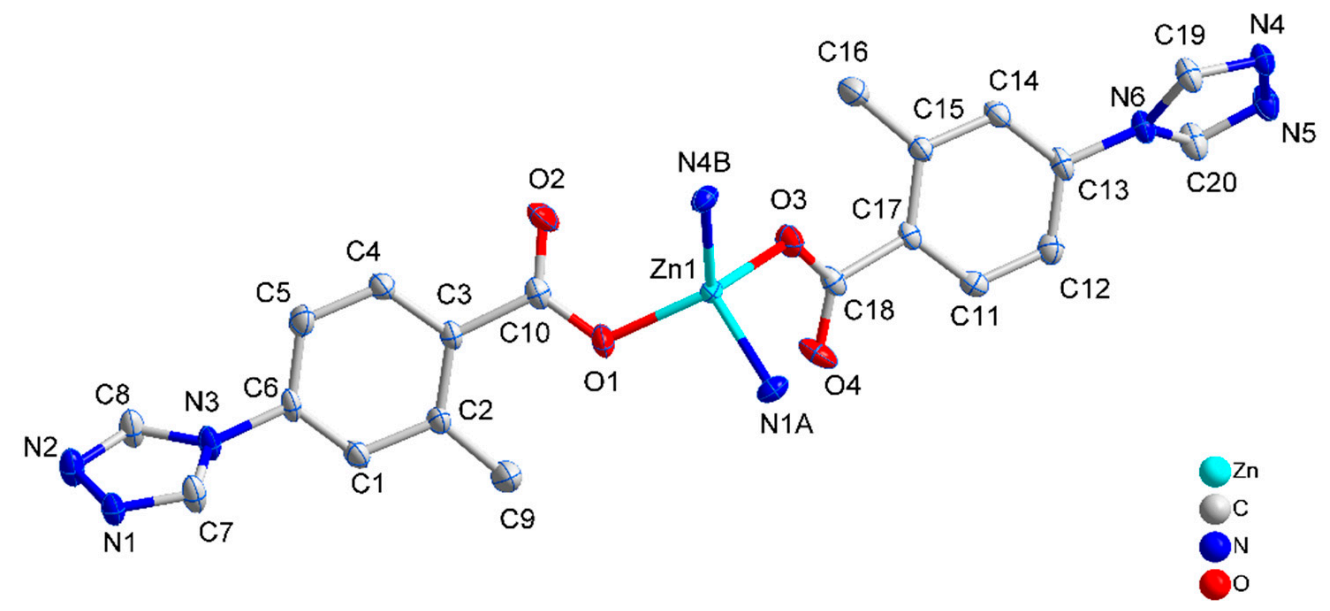

Figure 1. The coordination environment of $\mathrm{Zn}(\mathrm{II})$ ion in 1, with the ellipsoids drawn at the $30 \%$ probability level. All of the hydrogen atoms are omitted for clarity. Symmetry code: A $2.5-\mathrm{x}, 0.5+\mathrm{y}$, $1.5-\mathrm{z}, \mathrm{B} 0.5-\mathrm{x},-0.5+\mathrm{y}, 1.5-\mathrm{z}$.

\subsection{Thermal Analysis and Powder X-Ray Diffraction Analysis}

Thermogravimetric analysis (TGA) was performed to study the thermal stability of the coordination polymer in the $\mathrm{N}_{2}$ atmosphere from $20-700{ }^{\circ} \mathrm{C}$. Figure $\mathrm{S} 2$ shows no weight losses for the coordination polymer $\mathbf{1}$, and the collapse of the network happened at about $405^{\circ} \mathrm{C}$, which indicated the component of $\mathbf{1}$ has no lattice or coordinated water molecules or other organic components, completely fitting with crystal architecture of $\mathbf{1}$. The powder XRD experiment can be employed to measure the 
phase purity of the as-synthesized compound. As shown in Figure S3, the simulated sample from the crystal structure is quite consistent with the experimental pattern, indicating the phase purity of the sample.

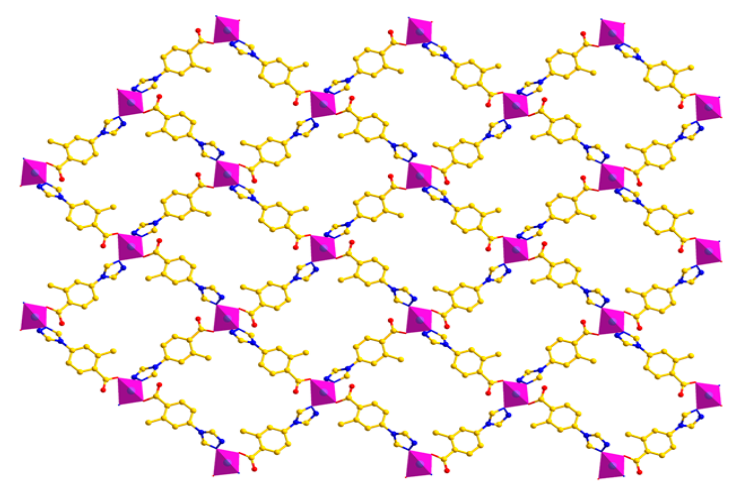

(A)

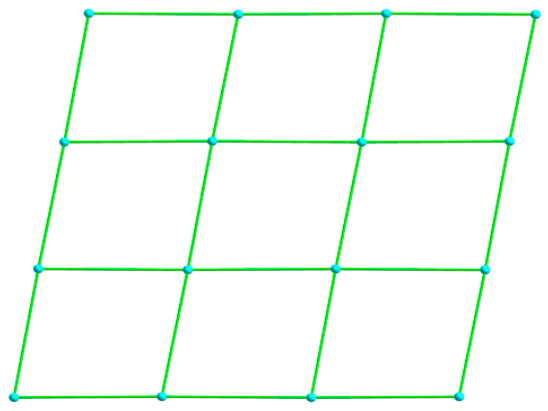

(B)

Figure 2. (A) 2D structure in 1. (B) A view of $(4,4)$ topology in $\mathbf{1 .}$

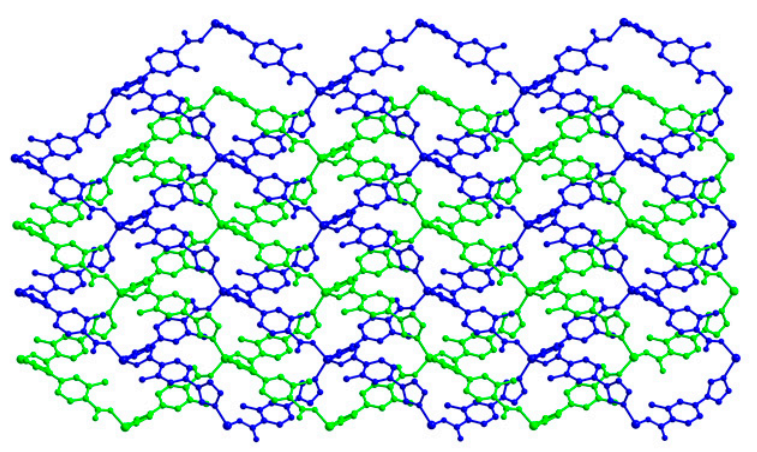

(A)

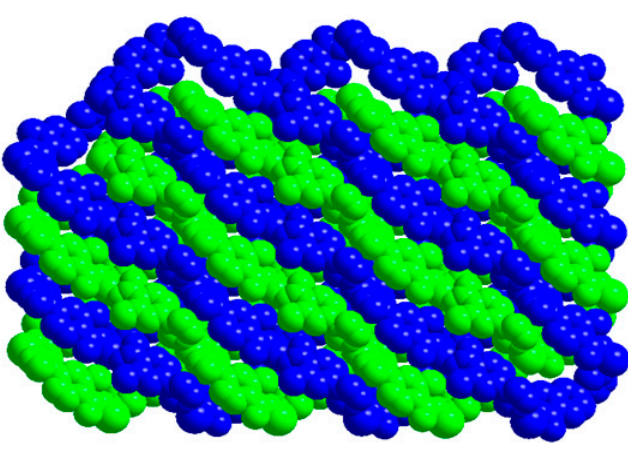

(B)

Figure 3. (A) The system of $2 \mathrm{D}+2 \mathrm{D} \rightarrow 2 \mathrm{D}$ parallel interpenetration in 1 (left); (B) Space-filling projection of parallel interpenetrated nets of $\mathbf{1}$ (right).

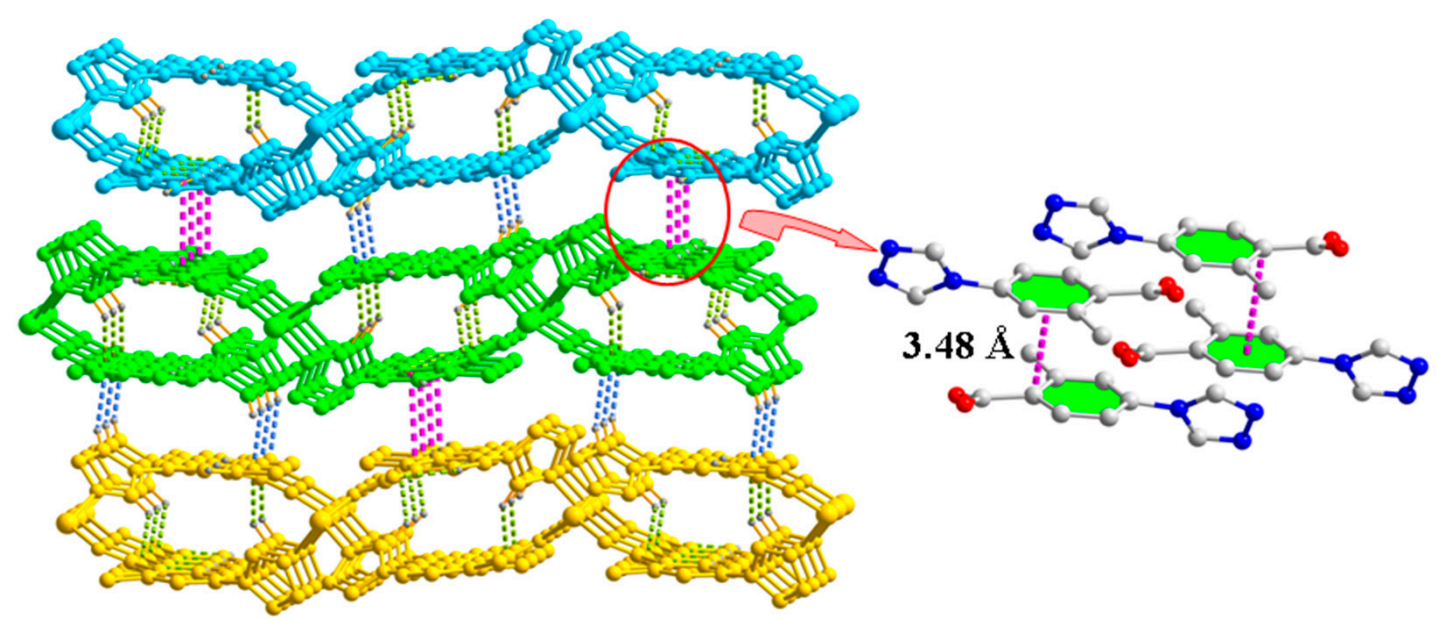

Figure 4. 3D coordination polymer of 1 packed by intramolecular and intermolecular hydrogen bonds and $\pi-\pi$ interactions with a centroid-centroid distance of $3.48 \AA$.

\subsection{Diffuse Reflectance Spectra}

The UV-visible spectroscopy was investigated for the complex $\mathbf{1}$, as well as the free ligand HL. As shown in Figure 5, the compounds HL and $\mathbf{1}$ exhibited absorption peaks at 305 and $304 \mathrm{~nm}$, 
respectively, which belong to $\pi \rightarrow \pi^{*}$ and $\mathrm{n} \rightarrow \pi^{*}$ transitions, due to the conjugate character of the organic molecule [33]. From the diffuse reflectance data, it can be easily transformed into a Kubelka-Munk function. And band gaps (Eg) can be obtained from the theory of optical absorption for a direct band gap semiconductor: $(\mathrm{Ah} v)^{2}=\mathrm{B}(\mathrm{h} v-\mathrm{Eg})$, where $\mathrm{B}$ is a constant corresponding to the material itself [34]. The Eg can be employed to evaluate the semiconductivity of the complexes. The Eg of $\mathbf{1}$ is estimated to be approximately $4.01 \mathrm{eV}$, which is obtained by extrapolation of the linear portion of the diffuse reflectance spectra (Figure 6), showing that $\mathbf{1}$ is an optical semiconductor [35].
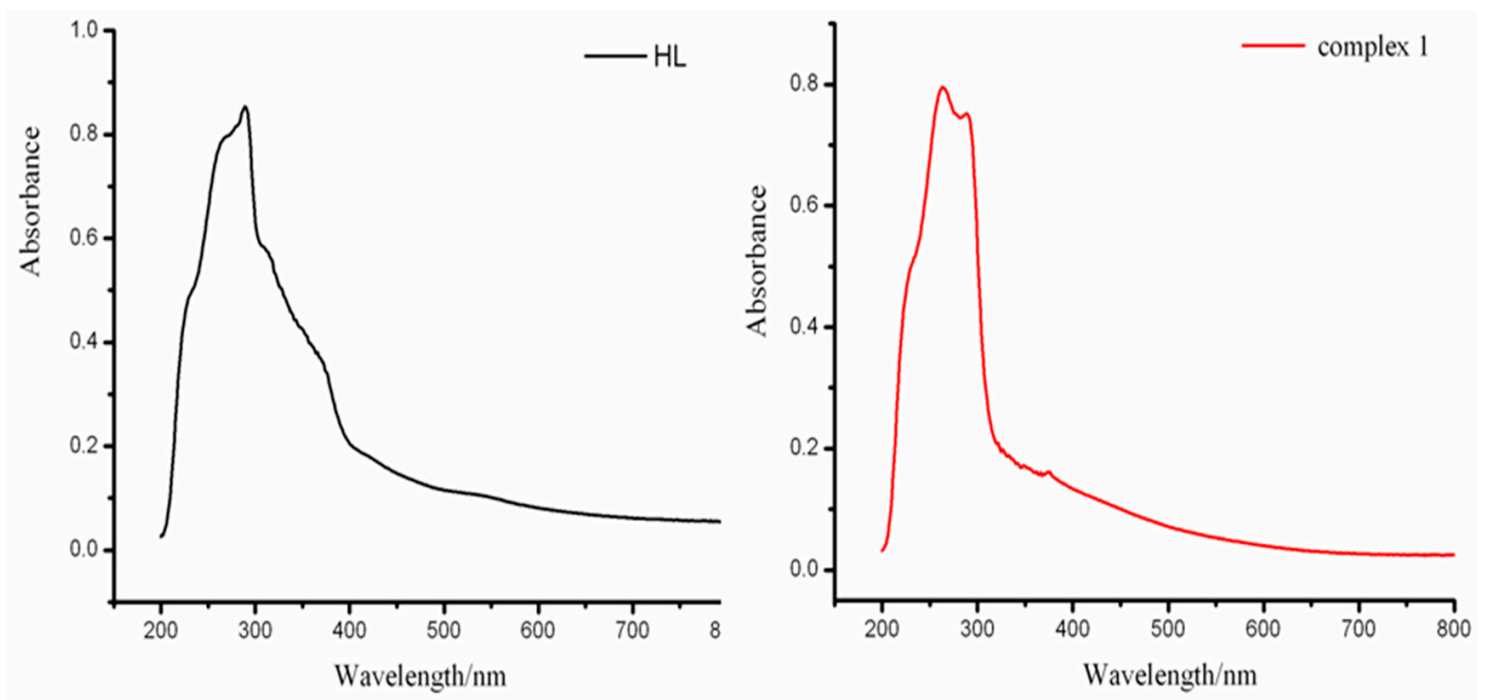

Figure 5. The UV-Vis spectra in the solid-state of HL and 1.

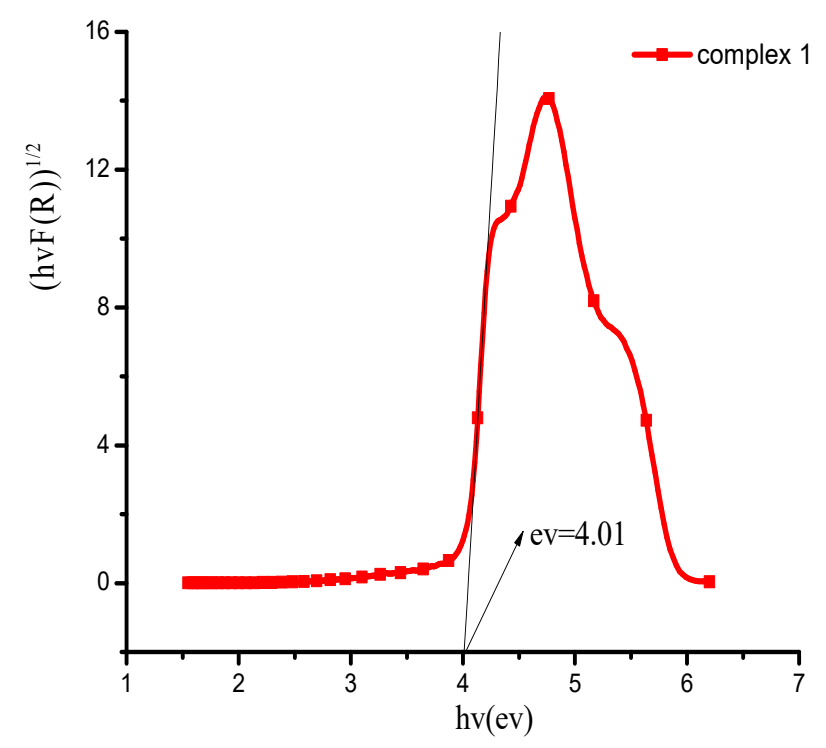

Figure 6. The band gap with $4.01 \mathrm{ev}$ by the treatment with the Kubelka-Munk function.

\subsection{Photoluminescent Property}

Luminescent CPs, especially containing $\pi$-conjugated organic molecules and a $\mathrm{d}^{10}$ metal center, can adjust the photoluminescent property through their interaction arising from metal and ligands [36,37]. Therefore, we performed the study of the photoluminescent properties of complex 1 together with HL organic ligand in the solid-state. As shown in Figure 7, the broad emission band at $433 \mathrm{~nm}$ was recorded for the HL organic molecule upon excitation at $365 \mathrm{~nm}$; this is attributable to $\pi^{*} \rightarrow \pi$ transition because of the $\pi$-conjugated effect of the aromatic group from the HL ligand [38]. Upon excitation at $365 \mathrm{~nm}$, compound 1 shows similar broad photoluminescence emission at $442 \mathrm{~nm}$. 
For the complex 1, the emission band is $9 \mathrm{~nm}$ red-shifted in contrast to the free HL ligand (Figure 7), which may be intraligand fluorescence due to their similarity $[39,40]$.

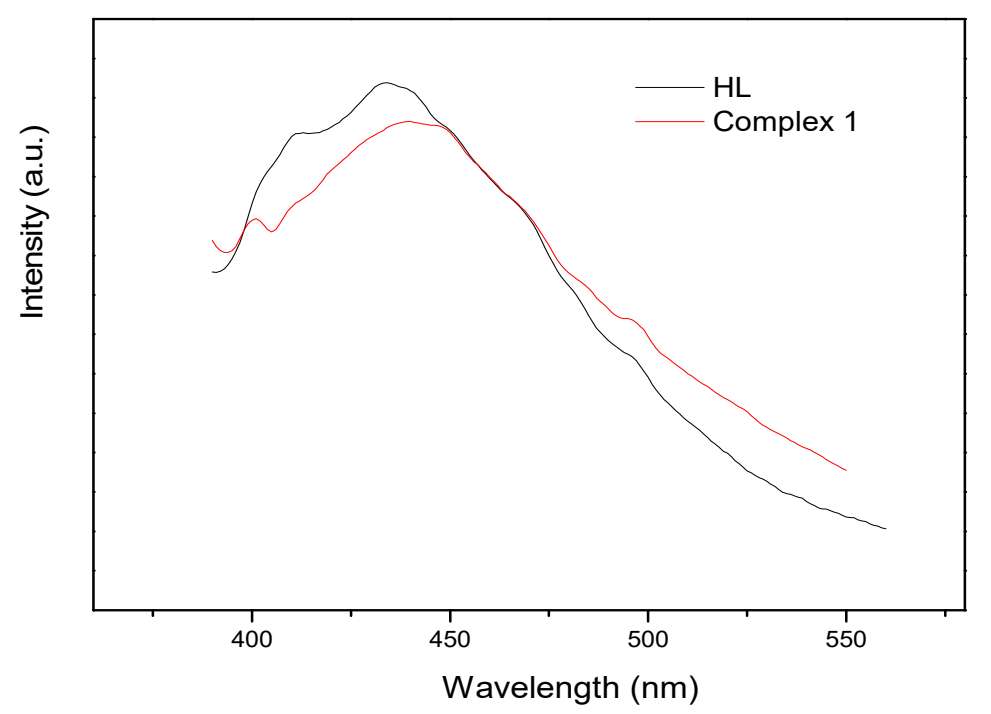

Figure 7. Solid-state photoluminescent spectra of HL ligand and complex 1.

Furthermore, we studied the corresponding decay lifetimes and quantum yield (QY) for the HL ligand and complex 1 . As shown in Figure 8, the QY value of compound 1 is $0.74 \%$. The QY value of coordination polymer $\mathbf{1}$ is $0.74 \%$. The QY value of compound $\mathbf{1}$ is probably attributed to the immobilization of the HL ligand, as it is strongly coordinated to metal ions that effectively increase the rigidity of the ligands, and to the low-dimensional structure with a $\pi$-conjugated system that decreases the molecular band gap [41]. Furthermore, the luminescence lifetime was also investigated for complex 1. The exponential function of $\mathrm{I}(\mathrm{t})=\mathrm{A} \exp (-\mathrm{t} / \tau)$ was employed to fit the luminescence decay curves, which shows the luminescence lifetime of $\mathbf{1}$ is 84 ns (Figure 9).

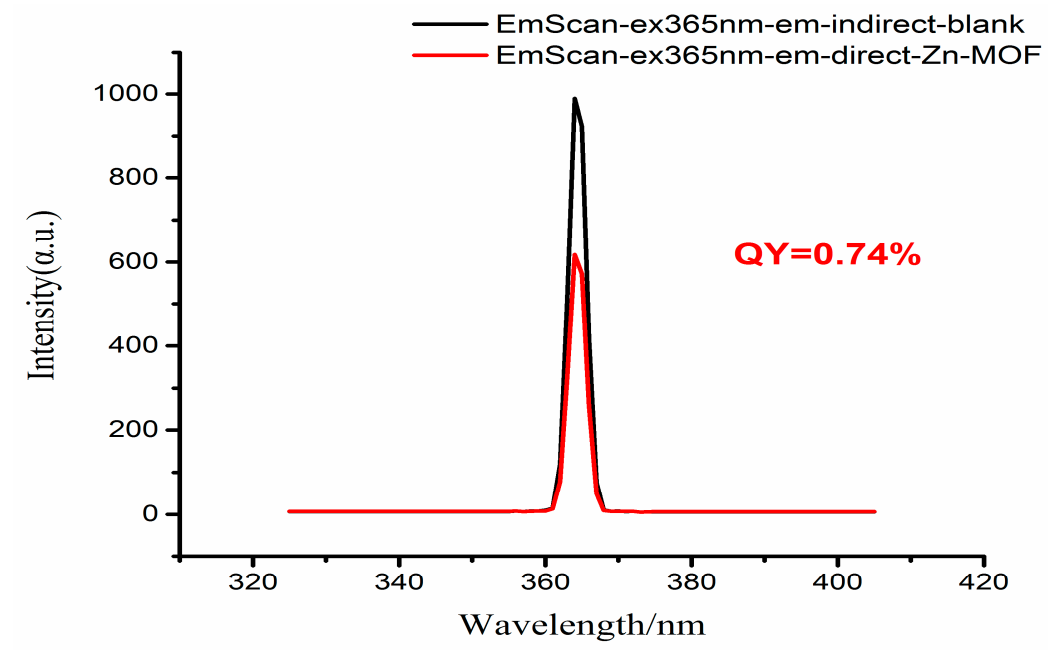

Figure 8. The quantum yield (QY) curve of complex $\mathbf{1}$. 


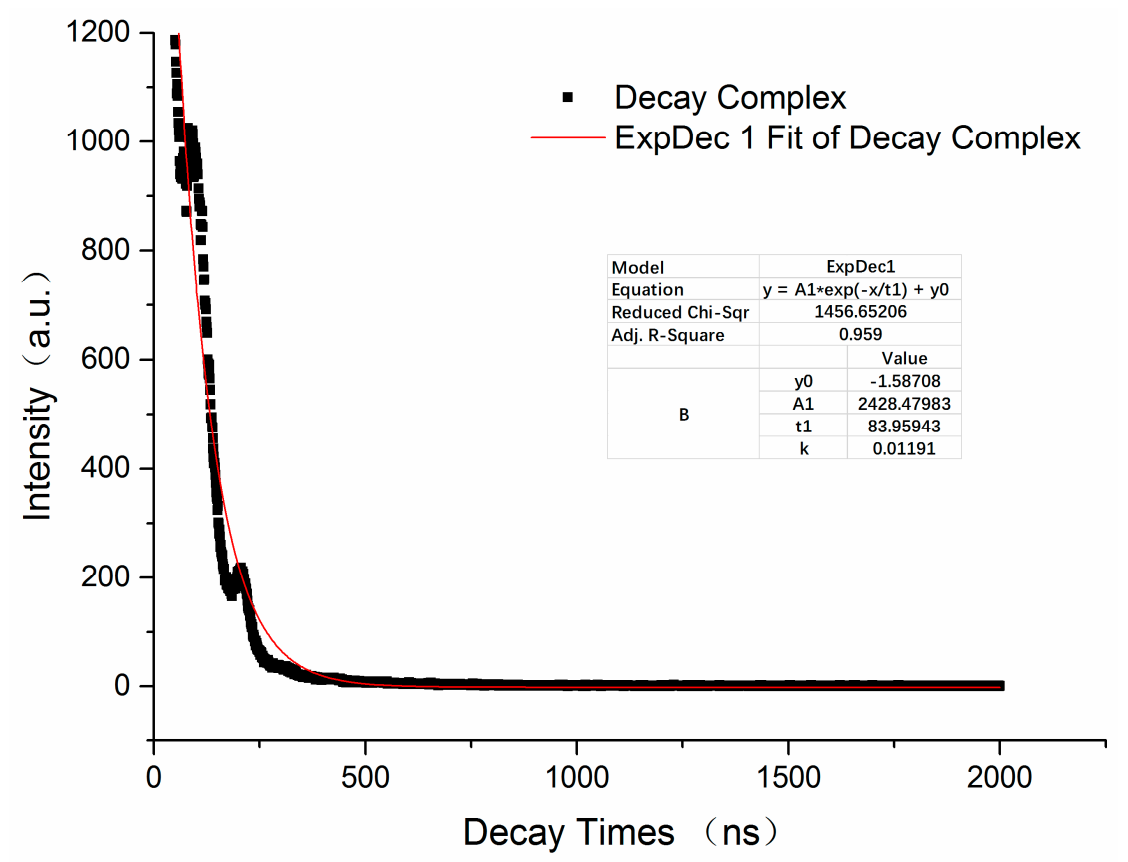

Figure 9. Luminescence decay curve for $\mathbf{1}$ (black line: experimental data; red line: fitting result).

\section{Conclusions}

A new coordination polymer $\left[\mathrm{Zn}(\mathrm{L})_{2}\right]_{n}$ was synthesized by the reaction of $\mathrm{Zn}$ (II) salt with an HL organic ligand including difunctional triazolyl and carboxyl groups. The deprotonated $\mathrm{L}^{-}$ligands act as linear two-connectors to link $\mathrm{Zn}^{2+}$ atoms to form a 2D layer structure. The large vacancy of the 2D framework allows another layer structure to interpenetrate, resulting in the system of $2 \mathrm{D}+2 \mathrm{D} \rightarrow 2 \mathrm{D}$ parallel interpenetration in $\mathbf{1}$. The coordination polymer 1 exhibits an emission at $442 \mathrm{~nm}$ upon excitation at $365 \mathrm{~nm}$. The luminescence lifetime and quantum yield of compound 1 are $84 \mathrm{~ns}$ and $0.74 \%$, respectively. The study has further demonstrated that the difunctional organic linkers containing triazolyl and carboxyl groups are effective moieties to generate desired architectures. The coordination polymer 1 shows good photoluminescence properties, and this study has further confirmed that CPs with the combination of $\mathrm{d}^{10}$ metal atoms and conjugated organic ligands could be potentially used as luminescent material.

Supplementary Materials: The following are available online at http:/ / www.mdpi.com/2073-4352/8/11/424/s1. Table S1. Selected bond lengths $(\AA)$ and bond angles $\left(^{\circ}\right)$ for $\left[\mathrm{Zn}(\mathrm{L})_{2}\right]_{\mathrm{n}}$. Table S2. Hydrogen bond lengths $(\AA)$ and

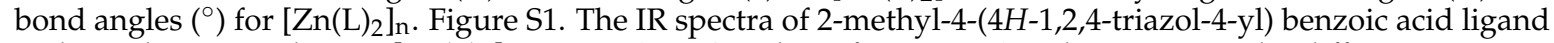
and coordination polymers $\left[\mathrm{Zn}(\mathrm{L})_{2}\right]_{n}$. Figure S2. TGA plots of 1. Figure S3. The X-ray powder diffraction pattern of $\left[\mathrm{Zn}(\mathrm{L})_{2}\right]_{\mathrm{n}}$.

Author Contributions: J.-L.L. and W.-D.L. synthesized the HL ligand. S.-S.H. and Z.-W.H. synthesized and characterized the $\mathrm{Zn}$ (II) coordination polymer. S.-S.C. guided the whole experiment.

Acknowledgments: This project was supported by the Natural Science Foundation of Colleges of Anhui Province (KJ2017ZD29).

Conflicts of Interest: The authors declare no conflict of interest.

\section{References}

1. Jiang, H.; Jia, J.; Shkurenko, A.; Chen, Z.; Adil, K.; Belmabkhout, Y.; Weselinski, L.J; Assen, A.H.; Xue, D.X.; O'Keeffe, M.; et al. Enriching the reticular chemistry repertoire: Merged nets approach for the rational design of intricate mixed-linker metal-organic framework platforms. J. Am. Chem. Soc. 2018, 140, 8858-8867. [CrossRef] [PubMed]

2. Hu, Z.; Deiberta, B.J.; Li, J. Luminescent metal-organic frameworks for chemical sensing and explosive detection. Chem. Soc. Rev. 2014, 43, 5815-5840. [CrossRef] [PubMed] 
3. Li, B.; Wen, H.M.; Wang, H.; Wu, H.; Tyagi, M.; Yildirim, T.; Zhou, W.; Chen, B. A porous metal-organic framework with dynamic pyrimidine groups exhibiting record high methane storage working capacity. J. Am. Chem. Soc. 2014, 136, 6207-6210. [CrossRef] [PubMed]

4. Martínez-Calvo, M.; Kotova, O.; Möbius, M.E.; Bell, A.P.; McCabe, T.; Boland, J.J.; Gunnlaugsson, T. Healable luminescent self-Assembly supramolecular metallogels possessing lanthanide (Eu/ $\mathrm{Tb})$ dependent rheological and morphological properties. J. Am. Chem. Soc. 2015, 137, 1983-1992. [CrossRef] [PubMed]

5. McCarney, E.P.; Byrne, J.P.; Twamley, B.; Martínez-Calvo, M.; Ryan, G.; Möbius, M.E.; Gunnlaugsson, T. Self-assembly formation of a healable lanthanide luminescent supramolecular metallogel from 2,6-bis(1,2,3-triazol-4-yl)pyridine (BTP) ligands. Chem. Commun. 2015, 51, 14123-14126. [CrossRef] [PubMed]

6. Wang, F.M.; Zhou, L.; Lustig, W.P.; Hu, Z.; Li, J.F.; Hu, B.X.; Chen, L.Z.; Li, J. Highly Luminescent metal-organic frameworks based on an aggregation-induced emission ligand as chemical sensors for nitroaromatic compounds. Cryst. Growth Des. 2018, 18, 5166-5173. [CrossRef]

7. Li, Y.W.; Yan, H.; Hu, T.L.; Ma, H.Y.; Li, D.C.; Wang, S.N.; Yao, Q.X.; Dou, J.M.; Xu, J.; Bu, X.H. Two microporous Fe-based MOFs with multiple active sites for selective gas adsorption. Chem. Commun. 2017, 53, 2394-2397. [CrossRef] [PubMed]

8. Zha, J.; Zhang, X. Room-temperature synthesis of two-dimensional metal-organic frameworks with controllable size and functionality for enhanced $\mathrm{CO}_{2}$ sorption. Cryst. Growth Des. 2018, 18, 3209-3214. [CrossRef]

9. Ji, P.; Drake, T.; Murakami, A.; Oliveres, P.; Skone, J.H.; Lin, W. Tuning lewis acidity of metal-organic frameworks via perfluorination of bridging ligands: Spectroscopic, theoretical, and catalytic studies. J. Am. Chem. Soc. 2018, 140, 10553-10561. [CrossRef] [PubMed]

10. Mo, Z.W.; Zhou, H.L.; Ye, J.W.; Zhou, D.D.; Liao, P.Q.; Zhang, W.X.; Zhang, J.P. Tuning connectivity and flexibility of two zinc-triazolate-carboxylate type porous coordination polymers. Cryst. Growth Des. 2018, 18, 2694-2698. [CrossRef]

11. Gao, X.; Zhang, S.S.; Yan, H.; Li, Y.W.; Liu, Q.Y.; Wang, X.P.; Tung, C.H.; Ma, H.Y.; Sun, D. A pillar-layered porous $\mathrm{Co}^{\mathrm{II}}$-MOF with dual active sites for selective gas adsorption. CrystEngComm 2018, 20, 4905-4909. [CrossRef]

12. Li, H.P.; Li, S.N.; Sun, H.M.; Hu, M.C.; Jiang, Y.C.; Zhai, Q.Z. Tuning the $\mathrm{CO}_{2}$ and $\mathrm{C} 1 / \mathrm{C} 2$ hydrocarbon capture and separation performance for a Zn-F-triazolate framework through functional amine groups. Cryst. Growth Des. 2018, 18, 3229-3235. [CrossRef]

13. Martínez-Calvo, M.; Pedriodo, R.; González-Noya, A.M.; Cwiklinska, M.; Zaragoza, G.; Bermejo, M.R. Chains of grids of cadmium(II) helicates? CrystEngComm 2012, 14, 4270-4273. [CrossRef]

14. Martínez-Calvo, M.; Pedrido, R.; González-Noya, A.M.; Romero, M.J.; Cwiklinska, M.; Zaragoza, G.; Bermejo, M.R. A sequentially assembled grid composed of supramolecular meso-helical nodes. Chem. Commun. 2011, 47, 9633-9635. [CrossRef] [PubMed]

15. Martínez-Calvo, M.; González-Noya, A.M.; Pedrido, R.; Romero, M.J.; Fernández, M.I.; Zaragoza, G.; Bermejo, M.R. A double-stranded dinuclear cadmium(II) helicate that assembles into chains in the solid state. Dalton Trans. 2010, 39, 1191-1194. [CrossRef] [PubMed]

16. Kim, H.; Yang, S.; Rao, S.R.; Narayanan, S.; Kapustin, E.A.; Furukawa, H.; Umans, A.S.; Yaghi, O.M.; Wang, E.N. Water harvesting from air with metal-organic frameworks powered by natural sunlight. Science 2017, 356, 430-434. [CrossRef] [PubMed]

17. Niuem, N.; Kong, L.; Zhao, Y.; Wu, H.; Li, J.; Langreth, D.C.; Chabal, Y.J. Spectroscopic evidence for the influence of the benzene sites on tightly bound $\mathrm{H}_{2}$ in metal-organic frameworks with unsaturated metal centers: MOF-74-cobalt. J. Am. Chem. Soc. 2011, 133, 4782-4784.

18. Zhang, Z.Y.; Xiao, L.; Chen, S.S.; Qiao, R.; Yang, S. A novel Zn(II) complex with 4-connected umc topology: Synthesis, crystal structure and luminescent property. Chin. J. Struct. Chem. 2017, 36, 819-824.

19. Dong, M.M.; He, L.L.; Fan, Y.J.; Zang, S.Q.; Hou, H.W.; Mak, T.C.W. Seven copper coordination polymers based on 5-iodo-isophthalic acid: Halogen-related bonding and $\mathrm{N}$-donor auxiliary ligands modulating effect. Cryst. Growth Des. 2013, 13, 3353-3364. [CrossRef]

20. Wang, W.; Wang, R.; Liu, L.; Wu, B. Coordination frameworks containing magnetic single chain of imidazole dicarboxylate-bridged cobalt(II)/nickel(II): Syntheses, structures, and magnetic properties. Cryst. Growth Des. 2018, 18, 3449-3457. [CrossRef] 
21. Chen, S.S.; Chen, M.; Takamizawa, S.; Chen, M.S.; Su, Z.; Sun, W.Y. Temperature dependent selective gas sorption of the microporous metal-imidazolate framework $[\mathrm{Cu}(\mathrm{L})]\left[\mathrm{H}_{2} \mathrm{~L}=1,4-\operatorname{di}(1 \mathrm{H}\right.$-imidazol-4-yl) benzene]. Chem. Commun. 2011, 47, 752-754. [CrossRef] [PubMed]

22. Chen, S.S.; Chen, M.; Takamizawa, S.; Wang, P.; Lv, G.C.; Sun, W.Y. Porous cobalt(II)-imidazolate supramolecular isomeric frameworks with selective gas sorption property. Chem. Commun. 2011, 47, 4902-4904. [CrossRef] [PubMed]

23. Furukawa, H.; Cordova, K.E.; O’Keeffe, M.; Yaghi, O.M. The chemistry and applications of metal-organic frameworks. Science 2013, 341, 974. [CrossRef] [PubMed]

24. Helal, A.; Yamani, Z.H.; Cordova, K.E.; Yaghi, O.M. Multivariate metal-organic frameworks. Nat. Sci. Rev. 2017, 4, 296-298. [CrossRef]

25. Tan, J.; Li, R.; Li, D.; Zhang, Q.; Li, S.; Zhou, H.; Yang, J.; Wu, J.; Tian, Y. Thiophene-based terpyridine and its zinc halide complexes: Third-order nonlinear optical properties in the near-infrared region. Dalton Trans. 2015, 44, 1473-1482. [CrossRef] [PubMed]

26. Zhu, M.A.; Guo, X.Z.; Xiao, L.; Chen, S.S. A new Cd(II) coordination compound based on 4-(1,2,4-Triazol-4-yl)phenylacetic acid: Synthesis, structure and photoluminescence property. Chin. J. Struct. Chem. 2018, 37, 437-444.

27. Chen, S.S.; Liu, Q.; Zhao, Y.; Qiao, R.; Sheng, L.Q.; Liu, Z.D.; Yang, S.; Song, C.F. New metal-organic frameworks constructed from the 4-imidazole-carboxylate ligand: Structural diversities, luminescence, and gas adsorption properties. Cryst. Growth Des. 2014, 14, 3727-3741. [CrossRef]

28. Sheldrick, G.M. A short history of SHELX. Acta Cryst. 2008, A64, 112-122. [CrossRef] [PubMed]

29. Liu, J.Q.; Wang, Y.Y.; Ma, L.F.; Shi, Q.Z.; Batten, S.R.; Proserpio, D.M. Generation of a 4-crossing [2]-catenane motif by the $2 \mathrm{D} \rightarrow 2 \mathrm{D}$ parallel interpenetration of pairs of $(4,4)$ sheets. CrystEngComm 2008, 10, 1123-1125. [CrossRef]

30. Chen, D.M.; Tian, J.Y.; Fang, S.M.; Liu, C.S. Two isomeric Zn(II)-based metal-organic frameworks constructed from a bifunctional triazolate-carboxylate tecton exhibiting distinct gas sorption behaviors. CrystEngComm 2016, 18, 2579-2584. [CrossRef]

31. Du, L.Y.; Wang, H.; Liu, G.; Xie, D.; Guo, F.S.; Hou, L.; Wang, Y.Y. Structural diversity of five new bitriazole-based complexes: Luminescence, sorption, and magnetic properties. Dalton Trans. 2015, 44, 1110-1119. [CrossRef] [PubMed]

32. Guo, X.Z.; Li, J.L.; Shi, S.S.; Zhou, H.; Han, S.S.; Chen, S.S. Synthesis, Structure and Luminescent Property of a Zn(II) Complex with Mixed Multi-N Donor and 2,5-Dihydroxy-terephthalic Acid Ligands. Chin. J. Struct. Chem. 2018, 37, 1117-1124.

33. Shi, Z.Q.; Guo, Z.J.; Zheng, H.G. Syntheses, crystal structures, and optical properties of five metal complexes constructed from a V-shaped thiophene-containing ligand and different dicarboxylate ligands. Dalton Trans. 2014, 43, 13250-13258. [CrossRef] [PubMed]

34. Yang, Y.J.; Wang, M.J.; Zhang, K.L. A novel photoluminescent Cd(II)-organic framework exhibiting rapid and efficient multi-responsive fluorescence sensing for trace amounts of $\mathrm{Fe}^{3+}$ ions and some NACs, especially for 4-nitroaniline and 2-methyl-4-nitroaniline. J. Mater. Chem. C 2016, 4, 11404-11418. [CrossRef]

35. Su, J.; Yao, L.; Zhao, M.; Wang, H.; Zhang, Q.; Cheng, L.; Tian, Y. Structural induction effect of a zwitterion pyridiniumolate for metal-organic frameworks. Inorg. Chem. 2015, 54, 6169-6175. [CrossRef] [PubMed]

36. Sun, Y.X.; Sun, W.Y. Zinc(II)- and cadmium(II)-organic frameworks with 1-imidazole-containing and 1-imidazole-carboxylate ligands. CrystEngComm 2015, 17, 4045-4063. [CrossRef]

37. Zhou, M.J.; Li, B.; Liu, L.; Feng, Y.L.; Guo, J.Z. Two polymorphs of zinc(II) coordination polymers constructed from 2-carboxyethyl(phenyl)phosphinate and 1,4-bis(1H-imidazol-1-yl)butane ligands. CrystEngComm 2014, 16, 10034-10039. [CrossRef]

38. Zeng, X.S.; Xu, H.L.; Xu, Y.C.; Li, X.Q.; Nie, Z.Y.; Gao, S.Z.; Xiao, D.R. A series of porous interpenetrating metal-organic frameworks based on fluorescent ligand for nitroaromatic explosives detection. Inorg. Chem. Front. 2018, 5, 1622-1632. [CrossRef]

39. Su, S.Q.; Qin, C.; Guo, Z.Y.; Guo, H.D.; Song, S.Y.; Deng, R.P.; Cao, F.; Wang, S.; Li, G.H.; Zhang, H.J. Five three/two-fold interpenetrating architectures from self-assembly of fluorene-2,7-dicarboxylic acid derivatives and $\mathrm{d}^{10}$ metals. CrystEngComm 2011, 13, 2935-2941. [CrossRef] 
40. Li, X.J.; Jiang, F.L.; Wu, M.Y.; Chen, L.; Qian, J.J.; Zhou, K.; Yuan, D.Q.; Hong, M.C. Construction of two microporous metal-organic frameworks with flu and PYR topologies based on $\mathrm{Zn}_{4}\left(\mu_{3}-\mathrm{OH}\right)_{2}\left(\mathrm{CO}_{2}\right)_{6}$ and $\mathrm{Zn}_{6}\left(\mu_{6}-\mathrm{O}\right)\left(\mathrm{CO}_{2}\right)_{6}$ secondary building units. Inorg. Chem. 2014, 53, 1032-1038. [CrossRef] [PubMed]

41. Ye, R.P.; Zhang, X.; Zhai, J.Q.; Qin, Y.Y.; Zhang, L.; Yao, Y.G.; Zhang, J. N-donor ligands enhancing luminescence properties of seven $\mathrm{Zn} / \mathrm{Cd}$ (II) MOFs based on a large rigid $\pi$-conjugated carboxylate ligand. CrystEngComm 2015, 17, 9155-9166. [CrossRef]

(C) 2018 by the authors. Licensee MDPI, Basel, Switzerland. This article is an open access article distributed under the terms and conditions of the Creative Commons Attribution (CC BY) license (http:/ / creativecommons.org/licenses/by/4.0/). 